\title{
Autism Spectrum Traits in Adults Affect Mental Health Status via Early Maladaptive Schemas
}

\author{
Fumiyo Oshima, \\ Hirofumi Nishinaka \\ Chiba University Graduate School of \\ Medicine, \\ Chiba, Japan \\ Kazunori Iwasa \\ Shujitsu University, \\ Okayama, Japan
}

\author{
Emi Ito, Eiji Shimizu \\ Chiba University Graduate \\ School of Medicine, \\ Chiba, Japan
}

\begin{abstract}
EMSs (early maladaptive schemas) may influence general health status and the development and maintenance of some psychiatric disorders. This study investigated whether early maladaptive schemas act as a mediator in the relationship between autistic traits and general health status in non-clinical adults. A cross-sectional questionnaire-based study was used. The AQ (Autism-Spectrum Quotient), YSQ (Young Schema Questionnaire), and GHQ (General Health Questionnaire) were administered to a non-clinical sample of 342 university students $(N$ $=342,238$ women and 112 men; mean age $=21.36$ years, $S D=5.17$ ). We found a significant relationship between autism spectrum traits and mental health, completely mediated by EMSs. Thus, higher autism spectrum trait scores predicted higher EMSs scores, which in turn predicted poorer mental health. Early maladaptive schemas appear to account for the mental health problems suffered by adults with autism spectrum traits. There are no additional data available.
\end{abstract}

Keywords: Autism spectrum traits, EMSs (early maladaptive schemas), mental health problems, mediation analysis

\section{Introduction}

The term ASDs (autism spectrum disorders) refers to a range of conditions such as Asperger's syndrome that are related to the core disorder of autism. These disorders are characterized by impaired social interaction, communication, and imagination, and individuals with these conditions often exhibit a rigid, repetitive pattern of behavior (Wing \& Gould, 1979).

ASDs are typically thought to affect mainly children. However, there are currently many adults with ASDs who were not identified as such when they were children, meaning that such individuals did not have the opportunity to receive early specialized intervention. Furthermore, some reports have indicated that such adults, particularly around adolescence or early adulthood - when they become more independent and more actively engaged in deep personal relationships - come to be quite self-conscious of their differences from other people. This can lead to reduced self-efficacy and self-esteem, which in turn can lead to depression and anxiety (Gaus,

Fumiyo Oshima, Research Center for Child Development, Chiba University Graduate School of Medicine.

Hirofumi Nishinaka, Division of Clinical Neuroscience, Chiba University Graduate School of Medicine.

Kazunori Iwasa, Department of Educational Psychology, Faculty of Education, Shujitsu University.

Emi Ito, Research Center for Child Development, Chiba University Graduate School of Medicine.

Eiji Shimizu, Research Center for Child Development, Chiba University Graduate School of Medicine. 
2007; Weiss \& Lunsky, 2010; White, Oswald, Ollendick, \& Schhill, 2009).

Some reports estimate that $70 \%-80 \%$ of adults with ASDs have comorbid mental problems such as mood, social anxiety, and obsessive compulsive disorders (Hamilton \& Morgan, 2011; Hofvander et al., 2009; Uno, Uchiyam, \& Osaka, 2009). Whereas many treatments for children with ASDs involve interventions that address particular autism spectrum traits, such as those interventions intended to improve recognition of social situations and social skills (Reichow, Barton, Boyd, \& Hume, 2012), almost all of the treatments available for adults with ASDs address only the comorbid mental health problems that these adults often exhibit. Indeed, there are no systematic treatments for mental health problems in adults with ASDs that actually take into account the characteristics of ASDs per se. In order to develop effective therapies for adults with ASDs who have comorbid mental problems, it may be most useful to determine what ASDs characteristics might serve as pathogenic mechanisms underlying these disorders. In this study, we are attempting to seek out this potential mechanism so that it can be used to enhance the treatment of adults with ASDs in Japan.

\section{Theory of EMSs (Early Maladaptive Schemas)}

The cognitive model—originally outlined by Beck (1967) — has generated a vast body of empirical research on psychopathology (Beck, 1967/1970; Clark, 1999; Willams, Richardson, Berkman, \& Tinetti, 1997). Research on the cognitive model in adults has recently experienced a revival through Young's (1994) schema theory (Young \& Klosko, 1994).

Schema theory is an alternative model that builds on Beck's original cognitive model (Beck, 1979; Young, 1999; Young, Klosko, \& Weishaar, 2003). Young proposed that a subset of schemas, called EMSs, form the core of longstanding psychological problems and personality disorders. Young's original taxonomy outlines 18 different EMSs grouped within five domains (see Table 1). The current definition of EMS is "a broad, pervasive theme or pattern comprised of memories, emotions, cognitions, and body sensations, regarding oneself and one's relationships with others, developed during childhood or elaborated throughout one's lifetime and dysfunctional to a significant degree" (Young et al., 2003). EMSs, therefore, lie at the deepest level of cognition and are formed of memories, intense emotions, and other internal experiences, which also accompany their activation.

Table 1

Young's (1998) EMSs

\begin{tabular}{|c|l|}
\hline Early maladaptive schema & Description \\
\hline Disconnection and rejection domain & $\begin{array}{l}\text { Expectations that one's needs for security, safety, stability, nurturance, } \\
\text { empathy, sharing of feelings, acceptance and respect will not be met in a } \\
\text { predictable manner }\end{array}$ \\
\hline Emotional deprivation & $\begin{array}{l}\text { The expectation that one's desire for a normal degree of emotional support } \\
\text { will not be adequately met by others }\end{array}$ \\
\hline Mistrust/abuse & $\begin{array}{l}\text { The expectation that others will hurt, abuse, humiliate, cheat, lie, } \\
\text { manipulate or take advantage }\end{array}$ \\
\hline Social isolation/alienation & $\begin{array}{l}\text { The feeling that one is isolated from the rest of the world, different from } \\
\text { other people, or not part of any group or community }\end{array}$ \\
\hline Defectiveness/shame & $\begin{array}{l}\text { The feeling that one is defective, bad, unwanted, inferior or invalid in } \\
\text { important respects or that one would be unlovable to significant others if } \\
\text { exposed }\end{array}$ \\
\hline Abandonment & $\begin{array}{l}\text { The perceived instability or unreliability of those available for support and } \\
\text { connection }\end{array}$ \\
\hline
\end{tabular}


(Table 1 to be continued)

\begin{tabular}{|c|c|}
\hline Early maladaptive schema & Description \\
\hline Impaired autonomy and performance domain & $\begin{array}{l}\text { Expectations about oneself and the environment that interfere with one's } \\
\text { perceived ability to separate, survive, function independently or perform } \\
\text { successfully }\end{array}$ \\
\hline Failure & $\begin{array}{l}\text { The belief that one has failed, will inevitably fail, or is fundamentally } \\
\text { inadequate relative to one's peers in areas of achievement }\end{array}$ \\
\hline Dependence/incompetence & $\begin{array}{l}\text { The belief that one is unable to handle one's everyday responsibilities in a } \\
\text { competent manner without considerable help from others }\end{array}$ \\
\hline Vulnerability to harm or illness & $\begin{array}{l}\text { The exaggerated fear that an imminent and unpreventable catastrophe will } \\
\text { strike at one's identity }\end{array}$ \\
\hline Enmeshment/undeveloped self & $\begin{array}{l}\text { Emotional over-involvement with significant others and insufficient } \\
\text { individuality }\end{array}$ \\
\hline Impaired limits domain & $\begin{array}{l}\text { Deficiency in internal limits, responsibility to others or long-term goal } \\
\text { orientation; leads to difficulty respecting the rights of others, cooperating with } \\
\text { others, making commitments or setting and meeting social interaction }\end{array}$ \\
\hline Insufficient self-control/self-discipline & $\begin{array}{l}\text { The pervasive difficulty or refusal to exercise sufficient self-control and } \\
\text { frustration tolerance to achieve one's personal goals, or control expression } \\
\text { of one's emotions }\end{array}$ \\
\hline Entitlement/grandiosity & $\begin{array}{l}\text { The belief that that one is superior to other people and entitled to special } \\
\text { rights and privileges }\end{array}$ \\
\hline Other-directness domain & $\begin{array}{l}\text { An excessive focus on the desires, feelings, and responses of others at the } \\
\text { expense of one's sense of connection or to avoid retaliation }\end{array}$ \\
\hline Self-sacrifice & $\begin{array}{l}\text { The excessive focus on voluntarily meeting the needs of others in daily } \\
\text { situations at the expense of one's own gratification }\end{array}$ \\
\hline Subjugation & $\begin{array}{l}\text { The excessive surrendering of control to others and subjugation of needs } \\
\text { and emotions to avoid anger, retaliation, or abandonment }\end{array}$ \\
\hline Approval-seeking/recognition-seeking & $\begin{array}{l}\text { The excessive inhibition of the expression of spontaneous action, feeling, or } \\
\text { communication }\end{array}$ \\
\hline Excessive vigilance and inhibition domain & $\begin{array}{l}\text { Excessive emphasis on suppressing one's spontaneous feelings, impulses, and } \\
\text { choices or on meeting rigid, internalized demands, often at the expense of } \\
\text { happiness, self-expression, relaxation, close relationships or health }\end{array}$ \\
\hline Negativity/pessimism & A pervasive, lifelong focus on the negative aspects of life \\
\hline Emotional inhibition & $\begin{array}{l}\text { The excessive inhibition of spontaneous action, feeling or communication, } \\
\text { usually to avoid disapproval by others, feelings of shame or losing control } \\
\text { of one's impulses }\end{array}$ \\
\hline Unrelenting standards/hypercriticalness & $\begin{array}{l}\text { The underlying belief that one must strive to meet very high internalized } \\
\text { standards of behavior and performance }\end{array}$ \\
\hline Punitiveness & $\begin{array}{l}\text { The belief that people who do not meet one's standards and exceptions } \\
\text { should be harshly punished }\end{array}$ \\
\hline
\end{tabular}

"Schema therapy" is an integrative approach to treatment that combines important aspects of cognitive-behavioral, experiential, interpersonal, and psychoanalytic therapies into one unified model. Schema therapy has shown remarkable results in helping people change EMSs that they have often lived with for many years (Masley, Gillanders, Simpson, \& Taylor, 2011; Nadort et al., 2009). Schema therapy is becoming an increasingly popular psychological model for working with individuals who have a variety of mental health and personality difficulties (Masley et al., 2011).

\section{Are Autistic Traits Associated With EMSs?}

EMSs and schema theory were originally applied to people with personality problems or full-blown personality disorders. However, some recent studies have indicated that EMSs mediate the relationships between parenting or attachment styles and psychiatric conditions (Roelofs, Lee, Ruijten, \& Lobbestael, 2011; Roelofs, Onckels, \& Muris, 2012; Turner, Rose, \& Cooper, 2005; Wright, Crawford, \& Del Castillo, 2009). Studies have suggested that highly active EMSs are a risk factor for various mental disorders such as 
post-traumatic stress disorder, bipolar II disorder, and eating disorders (Cockram, Drummond, \& Lee, 2010; Hawke \& Provencher, 2011; Unoka, Tolgyes, \& Czobar, 2007; Van Vlierberghe, Braet, Bosmans, Rosseel, \& Bögels, 2010). However, no study has examined whether EMSs play a role in mediating the relationship between mental health and autism spectrum traits.

The purpose of the present study was to verify whether EMSs mediate the association between autism spectrum traits and mental health status (see Figure 1), so that we might begin to understand the pathogenic mechanisms behind poor mental health in adults with ASD. We developed the following hypotheses: (1) higher scores on a measure of ASD traits will predict poor mental health; (2) higher scores on a measure of EMSs will predict poorer mental health; and (3) when controlling for EMSs, the relationship between ASD traits and mental health will become non-significant, such that the relationship between autism spectrum traits and mental health status is mediated by EMSs.

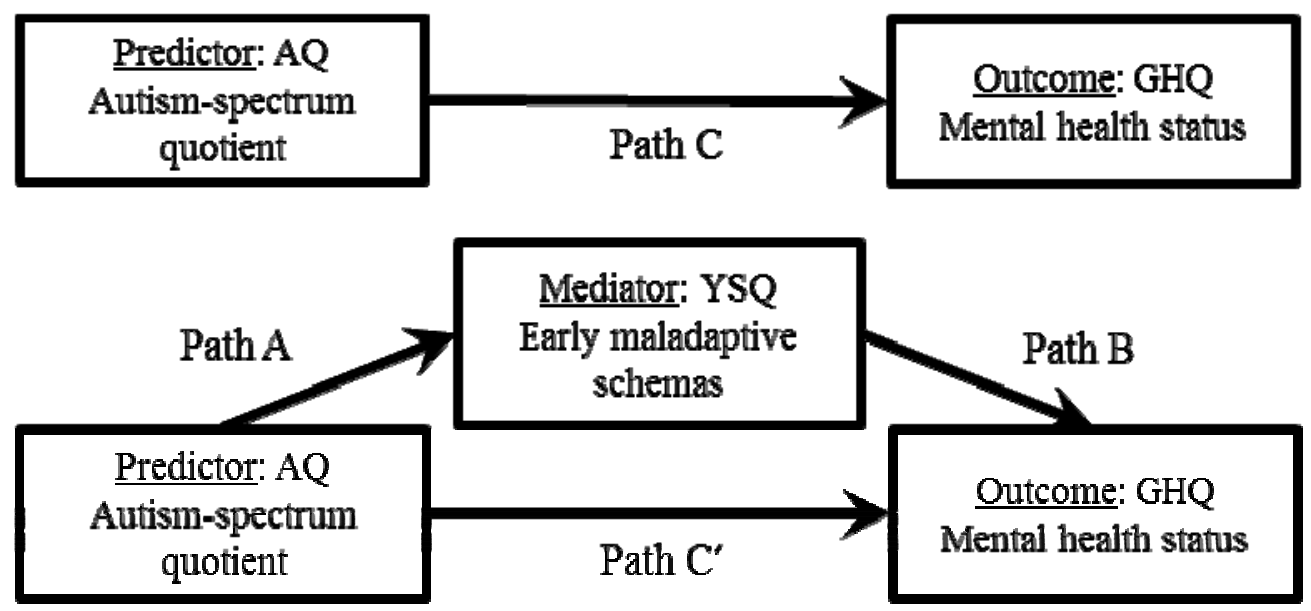

Figure 1. The hypothetical model examined in this study. The lower portion of this figure depicts the mediating role of early maladaptive schemas (as measured by the YSQ (Young Schema Questionnaire)) in the relationship between autism-spectrum traits (as measured by the AQ (Autism-Spectrum Quotient)) and mental health status (measured by GHQ-28 (the General Health Questionnaire)). The upper portion displays the relationship without the mediator.

\section{Method}

\section{Participants}

A total of 350 (238 women, 112 men) participants completed the study, recruited via an email invitation sent to student and staff mailing lists (undergraduate and master's levels) in 2011. Participants ranged from 18 to 55 years of age $(M=22.64$ years; $S D=5.83)$. The participants were selected according to the inclusion criterion of having no diagnosed psychiatric conditions for at least the past 12 months by their own self-report. Three participants who reported current histories of psychiatric disorders were excluded from analysis. Furthermore, five participants did not complete the questionnaires and so failed to provide data for analysis. This left a final sample of 342 participants ( 233 women, 109 men), between 18 and 55 years of age $(M=21.36$ years, $S D=5.17$ ).

Prior to the commencement of the study, all participants provided their written informed consent after receiving a full explanation of the nature of the study and the potential risks and benefits of participation. Participation was completely voluntary, and participants were informed that they could cease participation at any time. The study was approved by our ethics committee and was performed in accordance with the Declaration of Helsinki. 


\section{Measures}

All of the scales used were the Japanese language versions.

YSQ-S3J (YSQ-Short Form 3 Japanese version; Young et al., 2003, translated by Unehara et al., 2010, unpublished). The YSQ-S3 is a 90-item self-report inventory designed to assess the 18 EMSs (see Table 1) outlined by Young (1998). Participants choose the answer that best describes them on a 6-point Likert scale ( 1 = "Completely untrue", 6 = "This describes me perfectly"). Subscale scores are calculated by summing responses to the items for each specific EMS. Total YSQ-S3 scores are obtained by summing the scores of all subscales. The Japanese version of the YSQ-S3 translated by Umehara (11th Japanese Association for Cognitive Therapy Conference Proceedings, 2011) typically shows good to excellent internal consistency, with a Cronbach's alpha of 0.81 reported previously for the total scale scores. This was the case for the present study, with a Cronbach's alpha of 0.96.

AQ (Baron-Cohen, Wheelwright, Skinner, \& Clubley, 2001). AQ is a 50-item self-report questionnaire that assesses autistic traits. Participants indicate how true each statement is for them-"Definitely true", "Slightly true", "Slightly untrue", or "Definitely untrue". Specific statements for which autistic responses would be true were given a score of 1 if they were marked as true to any extent, and a score of 0 if marked untrue to any extent. Scoring was reversed for statements for which an autistic response would be untrue. Thus, the total range of possible scores is $0-50$, with higher scores indicating the presence of more autistic traits. The AQ contains five subscales: social skills, attention switching, attention to detail, communication, and imagination. The AQ has been shown to have reasonable face and construct validity (Baron-Cohen et al., 2001). Furthermore, it has been suggested that a cut-off of 32 or above serves to correctly identify people with autistic traits in the general population. Wakabayashi et al. (2004) adapted and standardized this questionnaire to apply to a Japanese population, and confirmed this version to be equivalent in terms of reliability and validity to the UK version (Wakabayashi, Tojo, Baron-Cohen, \& Wheelwright, 2004).

GHQ-28 (McDowell \& Newell, 1996). The GHQ-28 is typically used to assess psychiatric distress related to general medical illnesses. This 28 -item self-report questionnaire is designed to assess four aspects of distress: depression, anxiety, social impairment, and hypochondriasis. Participants indicate whether their current state of health differs from their usual state, thereby assessing relatively recent changes rather than lifelong personality characteristics. Participants responded according to their health state over the past two weeks. Participants evaluate the occurrence of the various concerns on a 4-point response scale. The scale points were anchored as follows: "Less than usual", "No more than usual", "Rather more than usual", and "Much more than usual". The first two types of answer are scored as "0" (Positive) and the second pair as "1" (Negative). Possible scores range from 0 to 28 , with higher scores indicating a greater probability of psychiatric distress. Total scores that exceeded 12 out of a possible 28 suggest probable distress (Chung, Preveza, Papandreou, \& Prevezas, 2006).

\section{Statistical Analysis}

The hypothetical model that we created to examine the potential mediating role of EMSs is based on the statistical method for mediation analysis suggested by Baron and Kenny (1986). This method uses regression analysis to investigate the mediating effect of a variable. As described in Baron and Kenny (1986), four statistical criteria must be present for a variable to be considered a mediator:

(1) The predictor variable must be significantly related to the mediator (Path A in Figure 1); 
(2) The predictor variable must be significantly related to the outcome variable (Path C);

(3) When the outcome is regressed simultaneously onto the predictor and mediator, the mediator must be significantly related to the outcome (Path B);

(4) When the mediator is controlled for, the relationship between the predictor and the outcome variables in the regression equation (Path $\mathrm{C}^{\prime}$ ) must be significantly attenuated compared with when the predictor is regressed only onto the outcome (i.e., Path C).

Baron and Kenny (1986) also recommended using a significance test to assess the indirect effect of the predictor on the outcome via the mediator. Path $\mathrm{C}^{\prime}$ shows the direct effect of AQ on GHQ-28 scores-That is, the portion of the predictor's influence on the outcome that is not mediated by EMSs. In contrast, the mediating or indirect effect is the portion of the influence of AQ on GHQ-28 scores that is mediated by EMSs; this is a synthetic index of Path A and Path B, and its confidence interval for the predictor can be estimated using the bootstrapping method. Thus, Path A represents the effect of AQ on EMSs, and Path B represents the effect of EMSs on GHQ-28 scores when controlling for the effect of AQ. If the indirect effect is statistically significant and satisfies the above criteria, then EMSs can be said to have a mediating effect on the relationship between AQ scores and GHQ-28 scores.

In summary, we used three regression equations to test the aforementioned hypotheses. In the first equation, GHQ-28 scores were regressed onto AQ scores (Path C). In the second equation, YSQ-SF3 scores were regressed onto AQ scores (Path A).

Finally, in the third equation, GHQ-28 scores were regressed onto AQ (Path $C^{\prime}$ ) and YSQ-SF3 (Path B) scores simultaneously.

To evaluate the statistical significance of these effects, we also estimated quasi-Bayesian $95 \%$ confidence intervals using the bootstrapping method. The regression analyses for testing our hypothetical model were performed using the "mediation" package (Hirose, Tingley, Yamamoto, Keele, \& Imai, 2013) for the statistical software R (Ihaka \& Gentleman, 1996).

\section{Results}

Complete mediation analysis results are presented in Table 2. On the first equation (Path C), the regression coefficient indicated that AQ had a significant positive effect on GHQ-28 scores $(\beta=0.144, t=2.68, p=0.008)$. On the second equation (Path A), AQ had a significant positive effect on YSQ-SF3 scores $(\beta=0.283, t=5.44$, $p<0.000$ ). On the third equation (Paths $\mathrm{B}$ and $\mathrm{C}^{\prime}$ ), YSQ-SF3 had a significant positive effect on GHQ-28 when controlling for AQ $(\beta=0.511, t=10.50, p<0.000)$. On the other hand, the effect of AQ on GHQ was no longer statistically significant after controlling for YSQ-SF3 $(\beta=0.000, t=0.000, p=1.000)$.

Table 2

Summary of Regression Analyses for the Hypothesized Mediation Model

\begin{tabular}{llllllrrl}
\hline Equation & Path & IV & DV & $\beta$ & $S E$ & \multicolumn{1}{l}{$t$} & \multicolumn{1}{l}{$R^{2}$} \\
\hline 1 & C & AQ & GHQ-28 & 0.144 & 0.054 & 2.68 & 0.008 & 0.018 \\
3 & A & AQ & YSQ & 0.283 & 0.052 & 5.44 & $<0.001$ & 0.077 \\
3 & B & YSQ & GHQ-28 & 0.511 & 0.049 & 10.50 & $<0.001$ & 0.257 \\
& C' $^{\prime}$ & AQ & GHQ-28 & 0.000 & 0.047 & 0.00 & 1.000 & \\
\hline
\end{tabular}

Notes. IV: Independent variable; DV: Dependent variable; SE: standard error; AQ: Autism-Spectrum Quotient; YSQ: Young Schema Questionnaire (assessment of early maladaptive schemas); GHQ-28: General Health Questionnaire. 
The decrease in the regression coefficient for the relationship between AQ and GHQ-28 scores when YSQ-SF3 was controlled for $(\beta=0.114 v s . \beta=0.000)$ is one indication that YSQ-SF3 scores had a mediating effect. Indeed, the regression coefficient was statistically significant before YSQ-SF3 scores were added into the equation, but the $p$-value rose above $p<0.05$ when YSQ-SF3 was added, with the relationship now becoming statistically insignificant. This condition is referred to as "full" or "complete mediation" (in contrast, partial mediation occurs when the path decreases but remains significant when controlling for the mediator). In addition, the amount of variance explained by GHQ-28 scores was larger in the third equation $\left(R^{2}=0.257\right)$ than in the first equation $\left(R^{2}=0.018\right)$. This can be regarded as another indicator of significant mediation.

Finally, we estimated the significance of the mediating and direct effects. The mediating effect of YSQ-SF3 on the relationship between AQ and GHQ-28 was $0.144(95 \% \mathrm{CI}=0.090-0.210)$. On the other hand, the direct effect was $0.000(95 \% \mathrm{CI}=-0.103-0.100)$. Moreover, the total effect (mediation effect + indirect effect) was $0.144(95 \% \mathrm{CI}=0.034-0.251)$. In general, we can regard an effect as statistically significant if the $95 \%$ confidence interval does not include zero, given that our null hypothesis for this mediation analysis was that there is no mediating effect. According to this criterion, both the mediating and total effects were statistically significant; however, the direct effect was not. Thus, because all of the criteria for mediation were present, we concluded that YSQ-SF3 scores serve as a mediator in the relationship between AQ and GHQ-28 scores.

\section{Discussion}

In this study, we investigated the mediating role of early maladaptive schemas or EMSs (as assessed by the Young Schema Questionnaire or YSQ-SF3) in the relationship between autism traits (as measured by the Autism Quotient or AQ) and general mental health (as measured by the GHQ-28 questionnaire). Our results show that EMSs fully mediate the relationship between autism-spectrum traits and mental health status, as we hypothesized on the basis of similar results in studies of other psychiatric disorders. That is, our results suggest that mental health status might deteriorate because of the negative effects of EMSs, rather than directly due to traits related to the autism spectrum.

Young et al. (2003) posited that EMSs are created through interactions between the environment experienced in the early stages of life and one's innate emotional temperament. Although our results were unable to elucidate the specific relationships between environment and EMSs, they do appear to suggest that EMSs are related to people's temperaments as per Young et al.'s (2003) theory. Furthermore, our results showed that people with autism spectrum traits tended to have no mental health problems when they had no or few EMSs. These results are consistent with the views of Baron-Cohen (2008) and Sugiyama (2011), who argue that ASD individuals in the absence of trauma or significant mental health problems can effectively no longer be considered to have ASD.

There thus appears to be little direct influence of autistic-spectrum traits on mental health status, with EMSs instead predicting later general and mental health difficulties in such individuals. Fortunately, however, EMSs are also subject to intervention. Gaus (2007) used CBT (cognitive behavior therapy) to treat mental health problems in patients with adult Asperger's syndrome. She found that mental health problems were ameliorated and quality of life improved when CBT was used to amend the cognitions and behaviors, including maladaptive schemas, of people with adult Asperger's syndrome. Furthermore, the core issue of adult Asperger syndrome did not disappear. Thus, although autism spectrum traits are likely a fairly permanent aspect of an individual's psychological makeup, the negative effects on health of these traits-brought about by their impact 
on EMSs - can be transformed by directly targeting the EMSs through schema therapy and CBT, with a corresponding improvement in individuals' health.

The present results suggest that autism per se does not have to constitute a clinical problem for the individual concerned, with a greater clinical concern being whether people develop negative core beliefs about the self, in response to poor treatment or difficulties fitting in. ASD should be viewed as a human individual difference variable rather than a core pathology that requires aggressive treatment. Leading from this is the question of which individuals with ASD are likely to develop EMSs and hence significant psychopathology.

One limitation of this study was that it used a non-clinical participant sample. This places real limits on the generalizability of our results and this study should be replicated using a patient sample. Nevertheless, this study opens the door to a host of future studies examining the presence and role of EMSs among people diagnosed with ASD; ultimately, this will lead to further improvements in schema therapy as a treatment option for these individuals.

\section{Conclusion}

Our results showed that autism spectrum traits in typically developing adults affect mental health status via EMSs; we found a meaningful relationship between EMSs and autism spectrum traits, indicating that changes in EMSs predict changes in mental health problems in people with these traits.

\section{References}

Baron, R. M., \& Kenny, D. A. (1986). The moderator-mediator variable distinction in social psychological research: Conceptual, strategic, and statistical considerations. Journal of Personality and Social Psychology, 51, 1173-1182.

Baron-Cohen, S., Wheelwright, S., Skinner, R., Martin, J., \& Clubley, E. (2001). The Autism-spectrum quotient (AQ): Evidence from Asperger syndrome/high-functioningautism, malesandfemales, scientistsand mathematicians. Journal of Autism and Developmental Disorders, 31, 5-17.

Baron-Cohen, S. (2008). Autism and Asperger syndrome-The facts. London: Oxford University Press.

Beck, A. T. (1967/1970). Depression: Causes and treatment. Philadelphia: University of Pennsylvania.

Beck, A. T. (1979). Cognitive therapy of depression. New York: Guilford.

Chung, M., Preveza, E., Papandreou, K., \& Prevezas, N. (2006). Spinal cord injury, posttraumatic stress, and locus of control among the elderly: A comparison with young and middle-aged patients. Psychiatry, 69, 69-80.

Clark, A. (1999). An embodied cognitive science? Trends in Cognitive Sciences, 3, 345-351.

Cockram, D., Drummond, P., \& Lee, C. (2010). Role and treatment of early maladaptive schemas in Vietnam veterans with PTSD. Clinical Psychology and Psychotherapy, 17, 165-182.

Gaus, V. L. (2007). Cognitive-behavioral therapy for adult Asperger's syndrome. New York: Guilford Press.

Gill, T. M., Williams, C. S., Richardson, E. D., Berkman, L. F., \& Tinetti, M. E. (1997). A predictive model for ADL dependence in community-living older adults based on a reduced set of cognitive status items. Journal of the American Geriatrics Society, $45,441$.

Hamilton, I., \& Morgan, H. (2011). What happens to people with ASD in middle age and beyond? Report of a preliminary on-line study. Advances in Mental Health and Intellectual Disabilities, 5, 22-28.

Hawke, L., \& Provencher, M. (2011). Schema theory and schema therapy in mood and anxiety disorders: A review. Journal of Cognitive Psychotherapy, 25, 257-276.

Hirose, K., Tingley, D., Yamatomo, T., Keele, L., \& Imai, K. (2013). R. Package for causal mediation analysis (Version 4.2.2) [Statistical Program for R]. Retrieved from http://cran.r-project.org/

Hofvander, B., Delorme, R., Chaste, P. et al. (2009). Psychiatric and psychosocial problems in adults with normal-intelligence autism spectrum disorders. BMC Psychiatry, 9, 35.

Ihaka, R., \& Gentleman, R. (1996). R: A language for data analysis and graphics. Journal of Computational and Graphical Statistics, 5(3), 299-314. 
Masley, S. A., Gillanders, D. T., Simpson, S. G., \& Taylor, M. A. (2011). A systematic review of the evidence base for schema therapy. Cognitive Behaviour Therapy iFirst article, 1-18.

McDowell, I., \& Newell, C. (1996). Measuring health: A guide to rating scales and questionnaires. New York: Oxford University Press.

Nadort, M., Arntz, A., Smit, J. H., Giesen-Bloo, J., Eikelenboom, M., Spinhoven, P., \& van Dyck, R. (2009). Implementation of outpatient schema therapy for borderline personality disorder with versus without crisis support by the therapist outside office hours: A randomized trial. Behaviour Research and Therapy, 47, 961-973.

Reichow, B., Barton, E. E., Boyd, B. A., \& Hume, K. (2012). Early intensive behavioral intervention (EIBI) for young children with autism spectrum disorders (ASD). Cochrane Database of Systematic Reviews (online). doi: 10.1002/14651858.CD009260.pub2

Roelofs, J., Lee, C., Ruijten, T., \&Lobbestael, J. (2011).The mediating role of early maladaptive schemas in the relation between quality of attachment relationships and symptoms of depression in adolescents.Behavior and Cognitive Psychotherapy, 39, $471-479$.

Roelofs, J., Onckels, L., \& Muris, P. (2012). Attachment quality and psychopathological symptoms in clinically referred adolescents: The mediating role of early maladaptive schema. Journal of Child Family Studies, 22, 377-385.

Sugiyama, T. (2011). Hattatsu-shogai no ima. Kodansha gendaisinsho (Developmental disorder today). Tokyo, Japan: Kodansha.

Turner, H. M., Rose, K. S., \& Cooper, M. J. (2005). Parental bonding and eating disorder symptoms in adolescents: The meditating role of core beliefs. Eating Behaviors, 6, 113-118.

Uno, Y., Uchiyam, T., \& Ozaki, Y. (2009). Medical care-related roles in the person with pervasive developmental disorder. Journal of Psychiatric Treatment, 24, 1231-1236.

Unoka, Z., Tölgyes, T., \& Czobor, P. (2007). Early maladaptive schemas and body mass index in subgroups of eating disorders: A differential association. Comprehensive Psychiatry, 48, 199-204.

Umehara, S. (2011, September). The Japanese version of the YSQ-S3. The 11th Japanese Association for Cognitive Therapy Conference Proceedings, Osaka, Japan.

Van Vlierberghe, L., Braet, C., Bosmans, G., Rosseel, Y., \& Bögels, S. (2010). Maladaptive schemas and psychopathology in adolescence: On the utility of Young's schema theory in youth. Cognitive Therapy and Research, 34, 316-332.

Wakabayashi, A., Tojo, Y., Baron-Cohen, S., \& Wheelwright, S. (2004). The Autism-Spectrum Quotient (AQ) Japanese version: Evidence from high-functioning clinical group and normal adults. ShinrigakuKenkyu: The Japanese Journal of Psychology, $75,78-84$.

Weiss, J., \& Lunsky, Y. (2010). Group cognitive behavior therapy for adults with Asperger syndrome and anxiety or mood disorders: A case series. Clinical Psychology and Psychotherapy, 17, 438-446.

White, S., Oswald, D., Ollendick, T., \& Scahill, L. (2009). Anxiety in children and adolescents with autism spectrum disorders. Clinical Psychology Review, 29, 216-229.

Wing, L., \& Gould, J. (1979). Severe impairments of social interaction and associated abnormalities in children: Epidemiology and classification. Journal of Autism and Developmental Disorders, 9, 11-29.

Wright, M. O., Crawford, E., \& Del Castillo, D. (2009). Childhood emotional maltreatment and later psychological distress among college students: The mediating role of maladaptive schemas. Child Abuse \& Neglect, 33, 59-68.

Young, J. E., \& Klosko, J. S. (1994). Reinventing your life: The breakthrough program to end negative behavior... and feel great again. New York: Plume Books.

Young, J. E. (1999). Cognitive therapy for personality disorders: A schema-focused approach (revised edition). Sarasota, F.L.: Professional Resource Press.

Young, J. E., Klosko, J. S., \& Weishaar, M. E. (2003). Schema therapy: A practitioner's guide. New York: Guilford. 